\title{
Práticas de leitura e escrita na contemporaneidade: uma produção multimodalizada
}

\author{
Sheilla Andrade Souza \\ Instituto Federal de Educação, Ciência e Tecnologia do Triângulo \\ Mineiro \\ souza_sh@hotmail.com \\ Maria da Glória Magalhães dos Reis \\ Universidade de Brasília \\ gloriamagalhaes@gmail.com
}

\section{Resumo}

O presente artigo é um recorte de uma pesquisa de mestrado desenvolvida no Programa de Pós-Graduação de Linguística Aplicada da Universidade de Brasília; objetiva apresentar uma proposta de produção escrita apoiada em reflexões sobre leitura e escrita na contemporaneidade. A proposta consistiu na produção de um pôster biográfico sobre o líder religioso Dalai Lama, com o propósito de criar oportunidades para os aprendizes desenvolverem capacidades escritas, assim como, fazerem uso de ferramentas digitais. Como metodologia foi utilizada a pesquisa-ação. Esperou-se que a atividade permitisse os aprendizes ampliarem o conhecimento de mundo a partir do desenvolvimento da leitura e da escrita em língua inglesa. Os dados revelaram que apesar das dificuldades, de uso da língua e manuseio das ferramentas digitais, os participantes realizaram a atividade proposta e houve uma ampliação do conhecimento de mundo através da língua inglesa.

Palavras-chave: Produção escrita. Ferramentas digitais. Modos semióticos.

\begin{abstract}
This article is an excerpt of a master's research developed at the Applied Linguistics Graduate Program at the University of Brasilia; It aims to present a a written production propose supported by reading and writing reflections on the contemporary society. The proposal was the production of a biographical poster on the religious leader Dalai Lama, in order to create opportunities for learners to develop written capacities, as well as make use of digital tools. The methodology used was an action research. It was expected that the activity
\end{abstract}


would allow learners to amplified the world knowledge from the development of reading and writing in English language. The data revealed that despite the difficulties of language use and handling of digital tools, participants performed the activity proposed and there was an expansion of knowledge of the world through the English language. Keywords: Written production. Digital tools. Semiotic modes.

\section{Introdução}

Partindo-se do consenso que há entre pesquisadores (MATTOS, 2011; ROJO, 2012) de que a escola precisa adequar-se às novas demandas sociais, visando atingir os objetivos educacionais, pontuamos a urgência de reformulação dos currículos escolares para que esses passem a contemplar uma nova geração de aprendizes denominada por Kalantzis e Cope (2012, p. 9) de "Geração Participatória" (doravante "Geração P"). Para esses autores, os aprendizes da Geração $\mathrm{P}$ deixam de ser passivos receptores de conhecimento para ser produtores do saber. São aprendizes que acessam as informações por meio de múltiplas fontes a qualquer momento e lugar e que não se restringem somente aos livros.

Assim sendo, para Walsh (2009, p.1) os alunos, atualmente, possuem acesso a uma variedade de tecnologias que os permitem desenvolver multitarefas a partir das ferramentas digitais e tecnologia móvel, como por exemplo: navegar na internet, enviar mensagens (áudio e texto), jogar, ouvir músicas e criar suas próprias listas de reprodução. Por isso, para a autora, estamos vivendo um momento de transição para as novas teorias e pedagogias, enquanto novas formas de comunicação digital emergem. Ainda de acordo com Walsh (2009, p. 2) "a sala de aula está em perigo a menos que mudanças significantes no currículo aconteçam".

Com isso, espera-se que as práticas pedagógicas sugeridas pelos currículos escolares almejem encorajar os aprendizes a participar ativamente na construção do saber, a responsabilizar-se pela própria aprendizagem, a ser capazes de resolver problemas, inovar, correr riscos de maneira consciente, superar desafios, além de serem criativos. Anseia-se, ainda, que os aprendizes trabalhem de maneira 
colaborativa, em pares ou em grupos, e que sejam capazes de atuar na sociedade como cidadãos multiletrados e críticos.

Apoiadas nessa perspectiva, desenvolvemos uma proposta pedagógica de ensino de língua inglesa por meio de gêneros textuais embasada nos princípios da sequência didática ${ }^{1}$. Pensamos as atividades de maneira tal, que elas dialogassem com as reflexões sobre práticas de escrita na contemporaneidade e que permitisse os participantes aprender ampliar o conhecimento de mundo através da língua inglesa, buscamos, também, verificar quais as dificuldades encontradas pelos aprendizes desta pesquisa, para realização da atividade. Neste artigo apresentaremos somente um recorte da pesquisa, que contemplou um exemplo de produção escrita - em tela do gênero biografia através de ferramentas digitais, a saber: inicialmente, pensada por meio do uso do "Glogster".

Propusemos a atividade em consonância com Kress (2003), que aborda a questão da escrita na era da tela, segundo o autor a escrita em tela está relacionada com a gramática visual (KRESS; van LEEUVEN, 1996, 2006) uma vez que os textos atuais precisam ter um bom aspecto visual. Para isso, o autor/escritor se apropria das ferramentas e recursos digitais disponíveis, tais como inserção de vídeos, cores, formas, diferentes letras e tamanhos, negrito, itálico e sublinhado entre outros, sendo que, de forma particular, a escrita atualmente é organizada em combinação com imagens - o texto ganha um novo layout, sendo assim, segundo Kress (2003, p. 20) a tela oferece diferentes possibilidades de organização textual.

Nessa perspectiva teórica Gunther Kress, ao lado de Theo van Leeuven, desenvolveu a Gramática do Design Visual (doravante GDV) publicada através do livro "Reading images: the grammar of visual design" em 1996. Reconhecemos a GDV, no entanto, informamos não ser o objetivo deste artigo aprofundar nas discussões referentes a ela, e

\footnotetext{
${ }^{1}$ Conceito para transposição didática cunhado por Dolz et al. (2004, p. 82), a saber: conjunto de atividades organizadas de maneira sistemática, tendo como base um gênero textual na modalidade oral ou escrita e cujo objetivo é incentivar os aprendizes, ao final da sequência de atividades, à produção do gênero estudado.

2 Ferramenta disponível online que permite criar pôster multimídia a partir de diferentes fontes de linguagem sendo eles: textos, imagens, fotografias, áudio (MP3), vídeos, efeitos especiais e outros elementos. Disponível em:

$<$ http://edu.glogster.com/?ref=com>.
} 
esclarecemos que as análises textuais realizadas neste trabalho não contemplam os elementos descritos pelos autores por meio GDV.

Na sequência, apresentaremos uma discussão sobre as práticas de leitura e escrita na contemporaneidade, iniciaremos nossas reflexões com os conceitos relevantes ao tema como: letramento, alfabetização, multiletramentos. Em seguida, apresentaremos a proposta de produção textual denominada como primeira produção. Logo após esta seção, explicaremos e analisaremos os dados coletados relacionados à produção do Pôster "Dalai Lama" e, por último, trataremos das considerações finais pertinentes à proposta apresentada.

\section{Práticas de leitura e escrita na contemporaneidade: revisão da literatura}

A fim de abordar as práticas de leitura e de escrita na contemporaneidade, isto é, em tela, faz-se necessário revisitar conceitos os quais nos permitem situarmos no contexto atual, recorremos a Kress $(2003$, p. 11) para quem a tela vem conduzindo a escrita em direção à visualidade.

Neste momento, trazemos para a discussão o termo letramento. Ele surgiu da necessidade de nomear uma nova categoria de leitores: aqueles que se apropriavam da leitura e escrita fazendo uso delas em práticas sociais, de forma que o conceito de leitor foi associado ao termo - competente - que designa aquele que lê, interpreta e atribui sentido ao que leu; e não somente um decodificador de signos linguísticos.

Dentro dessa visão, Soares (2010, p. 39-40) estabelece uma diferença entre indivíduo alfabetizado e indivíduo letrado, pois " [...] alfabetizado é aquele indivíduo que sabe ler e escrever"; letrado é aquele que vive em estado de letramento: além de ler e escrever, é capaz de usar socialmente a leitura e a escrita, as pratica e responde adequadamente às demandas sociais.

Nesse cenário, segundo Kress (2003) o termo letramento precisa ser revisto, pois encontra-se associado ao uso de letras (escrita alfabética), desvinculado de outros modos de comunicação advindos das novas mídias digitais. Igualmente, para Pimenta e Maia (2014, p. 128) "essa concepção de letramento é relativamente limitada, porque a 
comunicação e a representação não se realizam apenas e exclusivamente por meio da linguagem verbal". Seguindo essa linha de raciocínio, no capítulo introdutório do livro "The futures of literacy: modes, logics and affordances", Kress (2003) inicia suas ponderações afirmando não ser possível pensar em letramento de maneira isolada de fatores sociais, tecnológicos e econômicos. Tais fatores implicam em mudanças, dentre as quais Kress (2003) destaca duas, a primeira refere-se ao movimento do domínio da escrita para o domínio da imagem; e a segunda relaciona-se as mudanças do domínio dos livros para as telas.

$\mathrm{Na}$ visão do autor, essas mudanças juntas produzem uma revolução nas formas de representar e comunicar os significados. A partir daí, ele levanta dois questionamentos: (1) qual será o provável futuro do letramento; e (2) quais são os prováveis efeitos sociais e culturais de maior nível referentes a essa mudança? Assim sendo, a língua falada permanecerá como principal meio de comunicação e a língua escrita como sendo o modo preferido pelas elites políticas e culturais, todavia, à escrita será cada vez mais incorporadas imagens para efeito de produção de sentido.

Com base nas reflexões apresentadas, referimo-nos a Soares (2002) que pontua a necessidade de entender o termo letramento no plural e menciona o fato de tal posicionamento já estar sendo adotado em contexto internacional para designar os diferentes efeitos cognitivos, culturais e sociais em função ora dos contextos de interação com a palavra escrita, ora em função de variadas e múltiplas formas de interação com o mundo - não só a palavras escrita, mas também a comunicação visual, auditiva, espacial.

Nessa direção, Xavier (2005, p. 2), em seu artigo "Letramento digital e ensino", diz que o indivíduo plenamente letrado é capaz de "[...] enxergar além dos limites do código, fazer relações com informações fora do texto falado ou escrito e vinculá-las à sua realidade histórica, social, e política”. No dizer de Dionísio (2011, p. 138), "[...] uma pessoa letrada deve ser alguém capaz de atribuir sentido a mensagens oriundas de múltiplas fontes de linguagem, bem como ser capaz de produzir mensagens, incorporando múltiplas fontes de linguagem". Essas definições, em especial a de Dionísio, remetem ao surgimento e ao avanço no campo das tecnologias, sobretudo às tecnologias digitais. 
Conforme Dias (2012a, online), avançamos rumo aos multiletramentos, termo esse que, na visão de Kalantzis e Cope (2012), se refere a dois importantes aspectos da produção de sentido: o primeiro aspecto se refere à diversidade social ou à variabilidade de convenções de significados em diferentes situações sociais, culturais ou específicas de domínio. Para os autores os textos variam enormemente de acordo com o contexto social - experiência de vida, assunto, domínio disciplinar, área de trabalho, conhecimento especializado, aspectos culturais e identitários, a fim de nomear diferenças significativas.

Essas diferenças tornam-se mais relevantes à medida que interagimos em nossa vida cotidiana, produzimos e participamos dos significados. Daí a importância do ensino dos letramentos que busque ressignificar a ideia de que existe uma língua nacional única e padrão.

O segundo aspecto da produção de sentido, conforme Kalantzis e Cope (2012), recai sobre a multimodalidade, que constitui uma questão importante na contemporaneidade, em parte, devido ao aumento das mídias de informação e comunicação. Dessa forma, o significado passa a ser construído à medida que aumenta a multimodalidade, ou seja, aos modos linguísticos escritos passam a ser incorporados outros modos de construção de sentido, tais como o oral, o visual, o auditivo, o gestual, o tátil e o espacial. Posto de maneira mais clara, o termo multimodalidade é definido por Kalantzis e Cope (2012, p. 39) como sendo a combinação de diferentes modos de sentido, isto é: escrito, visual, espacial, tátil, auditivo e oral.

Vale dizer que a pedagogia dos multiletramentos foi firmada pela primeira vez por um grupo de dez autores internacionais falantes de inglês, advindos de países diferentes. Esses pesquisadores se reuniram durante uma semana no mês de setembro de 1994 em Nova Londres, New Hampshire, Estados Unidos. O grupo ficou conhecido como: Grupo de Nova Londres (doravante GNL), como mencionado no manifesto A pedagogy of multiliteracies - designing social future (isto é, uma pedagogia dos multiletramentos — desenhando futuros sociais). Na oportunidade, o grupo firmava a necessidade de a escola incorporar aos currículos pedagógicos os novos letramentos provenientes de uma sociedade contemporânea composta não somente pelo desenvolvimento das Novas Tecnologias de Informação e Comunicação (doravante TICs), como também pela diversidade cultural 
presente na sociedade como efeitos da globalização. Também dizia "[...] que essa juventude - nossos alunos — contava, já há quinze anos, com outras e novas ferramentas de acesso à comunicação e à informação e de agência social, que acarretavam novos letramentos, de caráter multimodal ou multissemiótico" (ROJO, 2012, p. 12-3).

O GNL estabeleceu uma diferença entre a pedagogia do letramento e a pedagogia dos múltiplos letramentos. Para eles a pedagogia do letramento remetia ao uso da linguagem centrado nela mesma, como um sistema estável, baseado em regras, havendo uma única forma nacional. Já a pedagogia dos múltiplos letramentos incorporam outros modos de representações da linguagem, que diferem de acordo com aspectos culturais e o contexto, além de ter efeitos cognitivos, culturais e sociais.

Essas reflexões nos fazem pensar no surgimento de um indivíduo multiletrado, o que permite-nos caminhar na mesma direção de Dias (2012a, on-line). Para ela um indivíduo multiletrado precisa

\section{[...] combinar múltiplas habilidades, conhecimento multicultural, comportamentos adequados aos diferentes contextos para exercer seus direitos e deveres de cidadão no presente e no futuro (DIAS, 2012a, on-line).}

Temos, então, a visão de um indivíduo reflexivo e consciente. Passando para as práticas de leitura e de escrita, por tradição eram executadas de maneira linear, em geral de cima para baixo e comumente impressas em papel. Nessa perspectiva, segundo Kress e van Leeuwen (2006, p. 205) "em texto impressos, leitura é linear e estritamente codificada", os autores afirmam que em textos impressos a leitura deve ser realizada da maneira que foi designada para ser - da esquerda para a direita e de cima para baixo - linha por linha (KRESS; van LEEUWEN 2006, p.205).

No entanto, na sociedade do presente repleta de novas tecnologias, ler e escrever incorpora, muitas vezes, a presença de uma tela, seja a de um computador, de um tablet, de um celular etc. — “[...] múltiplas fontes de linguagem" (DIONÍSIO, 2011, p. 138).

Em perspectiva atual, de leitura, descrita por Kress e van Leeuwen (2006, p.204), ela passa ser vista por um outro prisma, isto é, o texto pode ser lido de mais de uma maneira, o caminho de leitura é 
menos codificado e os caminhos podem ser múltiplos. Para os autores a leitura inicia pelo elemento mais saliente e segue para os próximos até que os significados sejam construídos. Entende-se por elemento saliente aquele que, de alguma maneira, se destaca no texto seja pela cor em destaque, pela posição ou pela nitidez (para melhor entender ver KRESS; van LEEUWEN 1996, 2006).

Por assim ser, em uma perspectiva contemporânea, o conceito de leitura se relaciona com o exercício de escolhas: "[...] leitura passa ser algo seletivo, parcial, dependendo do interesse ou do objetivo do leitor" (BRASIL, 2006, p. 106).

Nesse sentido, podemos dizer que o leitor também assume o papel de autor de sua leitura: a ele é dada a opção de escolher entre ler e/ou ouvir os diversos textos disponibilizados em uma única página/tela ou navegar entre páginas/telas por meio de links, conhecidos como hipertextos, que o conduzem a outras páginas/telas. Dessa forma, o leitor/autor constrói sua leitura.

Segundo Kress e van Leewen (2006, p. 205) o caminho de leitura é aquele escolhido pelo leitor sendo que "diferentes leitores podem seguir diferentes caminhos" (p.205), os autores afirmam: "leitura linear está perdendo gradualmente o espaço" (p.205). Dito isso, pode-se concluir que diante de um mesmo texto leitores distintos atribuem sentidos diversos e percorrem caminhos diferentes durante o processo de leitura, originando um novo tipo de letramento - o digital.

Letramento digital, para Dias (2012a, on-line), refere-se à “[...] capacidade do indivíduo para compreender e produzir textos orais e escritos no meio digital e para aplicar o conhecimento construído a outros contextos culturais". Para Xavier (2005), é de certa forma, uma luta contra a ideia de ensino-aprendizagem baseada na "educação bancária" (FREIRE, 1970), na qual o aprendiz é um receptor de informações e o professor, um provedor. $\mathrm{Na}$ perspectiva dos multi letramentos, sobretudo o digital, o aprendiz passa a ser visto como autor de sua aprendizagem e o docente, como um facilitador, colaborador. Segundo Xavier (2005, p. 3), o professor atual precisa ser

[p]esquisador, não mais repetidor de informação; articulador do saber, não mais fornecedor único do conhecimento; gestor de aprendizagens, não mais instrutor 
Sheilla Andrade Souza; Maria da Glória Magalhães dos Reis

de regras; consultor que sugere, não mais chefe autoritário que manda; motivador da "aprendizagem pela descoberta", não mais avaliador de informações empacotadas a serem assimiladas e reproduzidas pelo aluno (XAVIER, 2005, p.3).

Salientamos que nem sempre atuar como professor facilitador é tarefa fácil, uma vez que muitos de nós não fomos preparados para assumirmos tal postura. Todavia, ressaltamos a necessidade de nos adaptarmos, repensarmos nossas práticas pedagógicas e reformularmos os currículos escolares de maneira que estes estabeleçam um diálogo com as necessidades da sociedade atual, como já dissemos. A seguir, falaremos de maneira sucinta sobre o contexto da pesquisa e metodologia utilizada para realizá-la.

\section{Metodologia e contexto da pesquisa}

A metodologia utilizada para o desenvolvimento da pesquisa aqui relatada foi a pesquisa-ação (doravante P-A). Apoiamo-nos em uma visão de P-A autorreflexiva, elaborada e executada em forma de círculos espirais, os quais envolvem planejamento, ação, observação e reflexão (CARR; KEMMIS, 1986). A pesquisa foi desenvolvida durante o primeiro semestre letivo do ano de 2013 com aprendizes dos cursos de Informática, Eletrônica e Comércio da modalidade integrada e Informática da modalidade concomitante. Tais cursos foram ministrados em uma instituição pública federal localizada no interior de Minas Gerais.

Participaram da pesquisa um total de 114 aprendizes com idade entre 15 a 17 anos, conforme retratado pelo quadro abaixo. 
Quadro1: Total de participantes da pesquisa, divididos por turmas, sexo e idade.

\begin{tabular}{l|c|c|c|c}
\hline \multicolumn{1}{c|}{ Turma } & $\begin{array}{c}\text { N. de } \\
\text { participantes }\end{array}$ & Feminino & Masculino & Idade \\
\hline Informática Integrada & 33 & 16 & 17 & 15 a 17 \\
\hline Eletrônica Integrada & 33 & 8 & 25 & 15 a 17 \\
\hline $\begin{array}{l}\text { Turma de Comércio } \\
\text { Integrada }\end{array}$ & 27 & 21 & 6 & 15 a 17 \\
\hline Informática Concomitante & 21 & 10 & 11 & 15 a 17 \\
\hline \multicolumn{1}{c|}{ Total de Participantes } & 114 & 55 & 59 & \\
\hline
\end{tabular}

Fonte: SOUZA; REIS, 2014, p. 42

Quanto aos instrumentos para coleta de dados foram utilizados questionários, diário de bordo (aprendiz), diário de itinerância (professora-pesquisadora) e análise de atividades. Para este trabalho analisaremos somente o dados coletados por meio do Questionário 1, fonte pessoal (email) e amostras da primeira produção. Esclarecemos, em consonância com Souza e Reis (2014, p.43) que, em virtude do total de participantes, a saber: 114 (cento e quatorze) foi gerado um volume de dados o qual não contamos com espaço suficiente para apresenta-los e discuti-los na totalidade. Sendo assim,

após uma leitura analítica e criteriosa, agrupamos as informações que apresentavam ideias semelhantes e, desses grupos, selecionamos aquelas que - no nosso entendimento - eram pontuais para nossas discussões, e que, de alguma maneira, estabelecessem um diálogo com nosso suporte teórico. Porém, lembramos que selecionar os dados a serem apresentados não foi tarefa fácil, pois, assim como Bogdan e Biklen (1998, p. 158), sabemos que, diante do universo de dados, as "[...] escolhas são dificeis, sendo que tudo é interessante e o mundo o qual você estuda parece sem fronteiras (SOUZA; REIS, 2014 p.43).

Vale pontuar, ainda em consonância com Souza e Reis (2014) a pesquisa aqui descrita, é qualitativa de cunho interpretativista, sendo assim nos remete a Norton e Toohey (2011, p. 426), que ressaltam: a maneira com que cada pesquisador interpreta os dados não é única, 
sendo que as conclusões serão inevitavelmente parciais e situadas em um contexto específico, o que não desmerece a confiabilidade nem a veracidade dos resultados, tampouco o rigor da pesquisa.

É importante ressaltar que, por questões éticas, os nomes dos participantes utilizados neste trabalho são pseudônimos e os dados serão apresentados da maneira em que foram escritos para conservarmos a oringinalidade. Na sequência, passamos a relatar os procedimentos utilizados para a proposta da atividade e a apresentar as análises dos dados coletados de maneira concomitante.

4- Produção - Pôster Dalai Lama

A primeira produção consistiu na elaboração de um pôster biográfico sobre o líder religioso Dalai Lama e ocorreu, conforme a instrução a seguir:

Dalai Lama pôster ${ }^{3}$ : faça um pôster mostrando as diferentes fases da vida de Dalai Lama. Apresente seu pôster para os colegas de classe na aula seguinte. Quais foram as semelhanças encontradas entre você/seu grupo? Se você preferir, você pode fazer essa atividade utilizando o <http://www.glogster.com/ > e compartilhar no blog ou no grupo do facebook).

Essa atividade visou oportunizar os aprendizes o desenvolvimento de práticas de leitura e escrita através de ferramentas digitais.

Cabe dizer que para a produção do pôster foi sugerida a utilização da ferramenta disponível na internet no <http://www.glogster.com/>, porém alguns grupos alegaram dificuldades em acessá-la e manuseá-la. Nesse sentido, houve um momento em sala para os aprendizes compartilharem suas dúvidas com colegas a fim de buscar soluções de forma colaborativa sobre essa questão. Vale reforçar que a ferramenta apresentada pela professorapesquisadora foi somente uma sugestão, pois sabemos que nossos

3 THE DALAI LAMA POSTER: Make a poster showing the different stages of the life of the The Dalai Lama. Show your poster to your classmates in the next lesson. Did you/or your group all find out similar things? If you prefer, you can do this activity using <http://www.glogster.com/>, and share it on the blog or in the facebook group. 
alunos possuem conhecimentos de outras fontes que podem ser igualmente utilizadas. Achamos importante trazer a baila essa questão, pois reforçarmos o fato de que em uma pesquisa nem tudo acontece da maneira que foi programado e pode haver necessidade de replanejamento, situação essa possível uma vez que estamos realizando uma P-A. A partir de um replanejamento, foram fornecidas outras possibilidades e sugestões de ferramentas que poderiam ser utilizadas para realização da atividade proposta, como por exemplo, os softwares Word, Power Point e PhotoScape - este último sugerido por Danilo via e-mail. Vejamos!

Quadro 2: Dados coletados através de fonte pessoal - e-mail

\begin{tabular}{ll}
\hline P ART ICIPANTE & \multicolumn{1}{c}{ RELATO } \\
\hline Danilo & Boa noite, \\
& Professora Sheilla aqui é o aluno Danilo \\
& da turma [...]. Vem por meio deste lhe \\
& falar que alem daquele poster que eu te \\
& mandei que é meu, da [...] e da [...], eu fiz \\
& outro no programa PhotoScape eu achei \\
& que ficou bom. Estou mandando em anexo \\
& para saber sua opinião. Se quiser vale \\
& como uma dica de fazer os poster's sem \\
& usar o Glogster. Abraço. \\
& Att, \\
& Danilo (Sic) \\
\hline
\end{tabular}

Fonte: SOUZA, 2013, p. 88

O e-mail do participante materializa as concepções discutidas por Xavier (2005), apresentadas acima, referentes ao reposicionamento do professor no processo de construção do conhecimento. Na proposta desse autor, professores e aprendizes passam a trocar de experiências. Dessa forma, o professor é visto como aquele que sugere e não somente como detentor do saber. Assim, não mais é o chefe autoritário que ordena (XAVIER, 2005): passa a ser o motivador da aprendizagem pela descoberta e pelo 
compartilhamento de outras possibilidades de construção do saber. Sendo assim, ainda que em língua materna, Danilo teve a intenção de compartilhar o saber com os colegas, além de buscar informar a professora-pesquisadora sobre outras possibilidades que favorecem à construção do conhecimento.

Seguimos apresentando os procedimentos utilizados para a elaboração da primeira produção. Em data combinada a atividade deveria ser disponibilizada em um grupo do Facebook - criado pela professora-pesquisadora - com fins pedagógicos - ou enviada para o $e$ mail da professora-pesquisadora. A atividade também seria apresentada para os demais colegas de turma. Dessa forma, no dia da apresentação, os componentes do grupo deveriam explicar de que maneira a primeira produção contribuiu para a aprendizagem de língua inglesa e ampliação dos conhecimentos sobre o tema e o gênero escolhidos pela professora para a realização da aula. A apresentação poderia ser realizada em língua portuguesa, pois, naquele momento, seria avaliado se houve ampliação do conhecimento de mundo dos aprendizes e não somente das capacidades linguístico-discursivas.

Foi possível observar que os aprendizes se mostraram interessados pela vida do líder religioso e que ficaram surpresos em saber que, desde muito cedo, Dalai Lama já militava por questões sociais e religiosas. Com base nas apresentações, verificou-se a existência de um trabalho de pesquisa sobre o assunto, assim como o uso de recursos e ferramentas tecnológicas diversificadas. Ainda no que se refere à atividade, a ausência de trabalhos iguais permitiu deduzir que, possivelmente, não houve cópia de trabalho entre colegas, prática comum em alguns tipos de atividades.

Ao final das apresentações aplicou-se aos participantes um questionário com o objetivo de coletar informações complementares acerca da percepção deles quanto à realização da primeira produção "Pôster: biografia The Dalai Lama" bem como verificarmos se os aprendizes ampliaram o conhecimento de mundo através da língua inglesa. A seguir, passaremos para as reflexões acerca dos dados coletados por meio do Questionário $1^{4}$.

\footnotetext{
${ }^{4}$ Para acessar o questionário completo ver (SOUZA, 2013).
} 
Quadro 3: Dados coletados através do Questionário 1

\begin{tabular}{|c|c|}
\hline \multicolumn{2}{|c|}{$\begin{array}{l}\text { QUEST ÃO 1 } \\
\text { Em sua opinião a realização da atividade: "PÔSTER SOBRE } \\
\text { A BIOGRAFIA DO DALAI LAMA" ajudou-o a } \\
\text { desenvolver/melhorar sua aprendizagem de Língua Inglesa? } \\
\text { Em caso afirmativo, de que maneira? Em caso negativo relate } \\
\text { o que pode ser feito por você elou pela professora para que } \\
\text { você possa melhorar a aprendizagem de Língua Inglesa. }\end{array}$} \\
\hline Débora & $\begin{array}{l}\text { Sim, pois de maneira lúdica, o uso da língua } \\
\text { inglesa foi introduzida. (Sic) }\end{array}$ \\
\hline Fabiana & $\begin{array}{l}\text { Sim, acho que a iniciativa de trabalhar com a } \\
\text { atividade do pôster foi realmente importante para } \\
\text { meus conhecimentos sobre a Língua Inglesa, pois, } \\
\text { com está atividade nos possibilita a conhecer mais } \\
\text { o vocabulário da Língua Inglesa, aumentando } \\
\text { nosso conhecimento sobre o assunto. (Sic) }\end{array}$ \\
\hline Ronan & $\begin{array}{l}\text { Sim. Porque tive de usar ferramenta em inglês, e isso } \\
\text { ajuda no aprendizado. Também precisei pesquisar } \\
\text { sobre a biografia de alguém que eu não conhecia e } \\
\text { em um idioma que não sou tão familiarizada. (Sic) }\end{array}$ \\
\hline Robson & $\begin{array}{l}\text { Sim. Porque ajudou a escrever, melhor, e me } \\
\text { obrigou a desenvolver o meu inglês porque tive } \\
\text { que fazer pesquisa em inglês e isso me ajudou } \\
\text { muito a desenvolver o meu inglês. (Sic) }\end{array}$ \\
\hline Adriano & $\begin{array}{l}\text { Sim, pois através das traduções, pesquisas e muita } \\
\text { leitura, aprendi e compreendi mais um pouco da } \\
\text { língua inglesa. (principalmente em leitura de } \\
\text { textos em inglês). (Sic) }\end{array}$ \\
\hline
\end{tabular}

Fonte: SOUZA, 2013, p. 89

Com base nessas respostas, podemos perceber que a atividade contribuiu para a ampliação dos conhecimentos além das estruturas gramaticais. Para Fabiana, a atividade possibilitou aumentar vocabulário no que se refere à LI. Ronan afirma ter pesquisado sobre alguém que não conhecia e em um idioma não familiar, o que permite 
pensar que a pesquisa foi realizada em inglês. Débora aborda a questão do lúdico: a LI foi introduzida de maneira descontraída e prazerosa. Foi possível constatar, ainda, através das palavras "pesquisa/pesquisar" apresentadas nas respostas de Ronan, Robson, Adriano, que os alunos saíram da condição de passivo receptores do conhecimento para atuar como participante (KALANTZIS, COPE, 2012).

Embora a atividade proposta estivesse relacionada a práticas de escrita, os participantes revelaram a necessidade de se envolverem em práticas de leitura, o que nos remete ao que aponta Dias (2012b, p. 296): “[...] a fim de escrever, os alunos têm que ler — então leitura e escrita são vistos como processos indissociáveis". Nessa perspectiva, Bazerman (2011, p. 39) afirma que "[...] tarefas de escrita específicas podem ajudar os alunos a se tornarem leitores mais perceptivos e podem ajudar a destruir a tendência à falta de articulação ou à vagueza que resultam de uma leitura puramente privada". Portanto, no contexto escolar, às vezes, se refere à tarefa de leitura puramente para realização de um teste formal desvinculando o ensino da língua de seu caráter social.

\section{Pôster The Dalai Lama e as práticas de escrita contemporânea}

O período em que estamos vivendo configura-se por mudanças e transformações sociais, sobretudo no campo das tecnologias, demandando uma necessidade de o indivíduo desenvolver práticas de leitura e escrita que envolvam o uso das tecnologias digitais e das múltiplas linguagens (semioses). Dessa forma, a produção do "Pôster The Dalai Lama" foi analisada como base nas discussões apresentadas no início deste texto referente às práticas de leitura e escrita na contemporaneidade, para exemplificar, disponibilizaremos dois textos construídos pelos aprendizes que nortearam as análises no trabalho original. Conforme segue. 
Figura 1: Amostra das primeiras produções: pôster "The Dalai Lama" - Produção 1

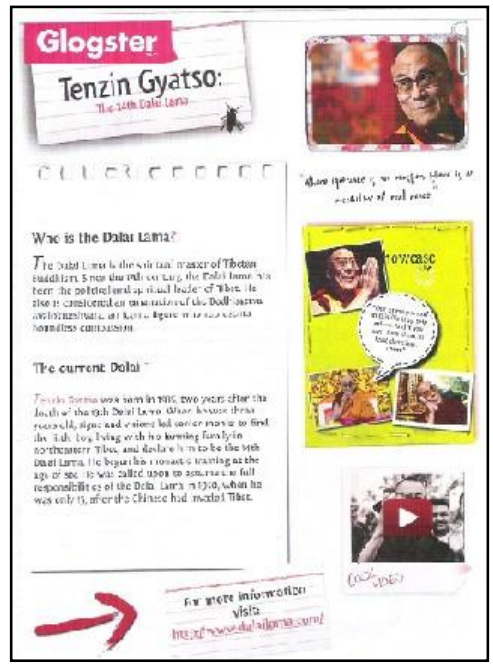

Fonte: SOUZA, 2013, p. 100
Figura 2: Amostra das primeiras produções: pôster "The Dalai Lama” - Produção 2

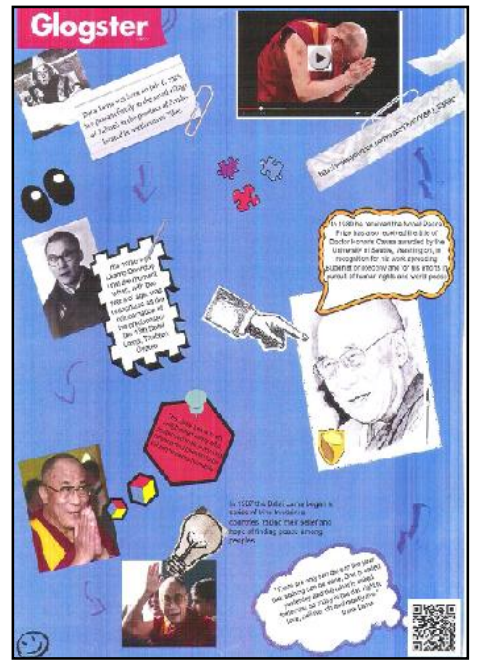

Fonte: SOUZA, 2013, p. 100

Os exemplos acima permitem dizer que os textos construídos pelo uso de ferramentas digitais, constituem-se não só pela escrita alfabética como também por imagens, sons, figuras geométricas e outros. Informamos que as produções podem ser visualizadas com maior precisão no seguinte endereço: <http://sheillateacher.blogspot.com.br/>.

As duas produções foram construídas a partir de elementos semióticos diversos, como por exemplo, uso de linguagens (semioses) verbais e não verbais, página organizada de maneira diversificada e criativa, recursos gráficos, efeitos visuais, cores, vídeo e outros. É importante ressaltar que, embora as duas produções tenham partido de uma mesma proposta, pode-se constatar que os textos se apresentam diversamente quanto à forma como foram organizados na página/tela e aos elementos usados para a construção da mensagem.

No texto da Figura 1, os autores organizaram a mensagem escrita voltada mais para a direita e de maneira próxima à sequencial. No texto da Figura 2, a mensagem escrita se encontra disposta em vários 
blocos de texto e dentro de diferentes formas, o que leva a pensar no que diz Kress (2006, p. 205) "os caminhos de leitura podem ser circulares, diagonais, espirais e assim por diante". Nessa mesma linha de raciocínio, para Soares (2002, p. 150): a escrita em tela possibilita construir um texto diferente dos produzidos em papel — o chamado hipertexto; o texto nessa perspectiva é "[...] escrito e é lido de forma multilinear, multissequencial, acionado de links ou nós que vão trazendo telas numa multiplicidade de possibilidades, sem que haja uma ordem predefinida". Tais características podem ser percebidas em ambas as produções: temos a presença de hiperlinks, os quais permitem ao leitor elaborar seu próprio caminho de leitura: o leitor-autor poderá ler ou assistir/ouvir a mensagem na ordem que desejar. As palavras de Soares (2002, p. 150) são esclarecedoras aqui: “[...] o hipertexto [...] tem a dimensão que o leitor lhe der: seu começo é ali onde o leitor escolhe, com um clique, a primeira tela; termina quando o leitor fecha, com um clique, uma tela, ao dar-se por satisfeito ou considerar-se suficientemente informado".

Ainda na perspectiva da leitura e escrita não linear, a maneira com que os autores organizaram os textos 1 e 2 (FIG. 1 e 2) dialoga com Mattos (2011, p. 36): encontramos “[...] vários textos pequenos, relacionados ou não, dispostos em pontos diferentes da mesma página". Todavia, entender com maior clareza a mensagem requer que o leitor-autor combine múltiplas capacidades a fim de construir significados. Outro aspecto observado se refere à noção de gênero apresentada por Marcuschi (2011, p. 19) como algo flexível, variável, interativo e multimodalizado: muda, funde-se, mistura-se para manter sua identidade funcional com inovação organizacional; assume "caras novas" (ANTUNES, 2009, p. 55).

As discussões anteriores levam a concluir que, embora os textos tenham sido organizados de maneira não tradicional - não sequencial, não linear, deixando de obedecer aos padrões que consistem em uma leitura-escrita da esquerda para a direita e de cima para baixo - ao observá-los podemos perceber aspectos que permitem classificá-los como pertencentes ao gênero biografia, tais como as fotos representando diferentes fases da vida de Dalai Lama e dados do nascimento, da família e da vida adulta.

A fim de verificarmos as dificuldades encontradas pelos aprendizes desta pesquisa, para realização da atividade proposta elaboramos um questionário, denominado Questionário 1, na 
sequência, apresentaremos e discutiremos os dados coletados através dele.

Quadro 4: Dados coletados através do Questionário 1

\section{QUESTÃO 2}

Quais as dificuldades encontradas por você/grupo para realizar a atividade?

Senti dificuldade para usar o site "glogster" pois o site

Anne é todo em inglês e eu não sabia onde começar, o que fazer, mas depois fui pesquisando e consegui realizar o trabalho. (Sic)

Mecher no programa, porque ele estava na versão em

Renata inglês, e a dificuldade de pesquisar em inglês, mas apesar das dificuldades, foi muito bom realizar o trabalho, e foi grande o meu aprendizado. (Sic) As minhas dificuldades foram na hora de tradução do

Renato português para Inglês, e também, tive um pouco de dificuldade na ferramenta usada, mas é porque nunca tinha utilizado antes. (Sic)

Fábio Acessar o glogster e traduzir expressões e frases para o inglês.

Fabrício Dificuldade ao traduzir as frases e a montar o trabalho de uma forma criativa. (Sic)

Fonte: SOUZA, 2013, p. 101

Os dados selecionados possibilitam perceber que os aprendizes apresentaram dificuldades em usar ferramentas digitais para realização das atividades. Somente Fabrício não mencionou ter enfrentado problemas para acessar a ferramenta, porém menciona ter encontrado dificuldade em organizar o texto de maneira criativa. Apesar de os participantes terem relatado dificuldades, verifica-se que foram superadas, como sugerem as produções e o caminho percorrido para construírem o texto: recorrendo a outras ferramentas que não as sugeridas pela professora-pesquisadora. Tal dificuldade pode ser justificada com o relato de Renato: "[...] é porque nunca tinha utilizado 
antes". Curiosamente, Anne e Renata relacionaram a dificuldade com o idioma da ferramenta: o inglês, o que nos permite inferir que os aprendizes fizeram uso da LI em práticas discursivas envolvendo contexto real de uso, remetendo, assim, ao caráter vivo e heterogêneo da língua.

Outro ponto merece destaque: a conformidade entre os participantes sobre a dificuldade de traduzir palavras do português para o inglês, os participantes tiveram de encontrar estratégias que os levassem à superação e a um resultado final de produção satisfatório. Essa atitude dialoga com Bazerman (2011): quando os aprendizes são envolvidos em territórios de aprendizagem específicos e desenvolvem estratégias bem-sucedidas, tornam-se aptos a transferir as experiências adquiridas quando envolvidos em outras situações de práticas discursivas. Adiante, com base nas discussões anteriores, prosseguimos com a análise da questão 5 do Questionário 1.

Quadro 5: Dados coletados através do Questionário 1

\section{QUESTÃO 5}

Quais os recursos você/grupo utilizou para construir o texto? (Vídeos, linguagem verbal, fotos, desenhos). Em sua opinião a opção de poder utilizar outros recursos que não somente a linguagem verbal contribui para o processo de aprendizagem? Justifique.

Vídeos, fotos, linguagem, e desenhos. Contribuíram Alberto para aprendizagem. Pois eu não sabia que existia esta ferramenta. (Sic)

Vídeos, linguagem verbal, fotos, desenhos. Sim, já que

Raul o pôster fica mais legal, animado, e bonito, chamando atenção das pessoas. (Sic)

Rebeca Imagem e texto. Sim dando + interação cl o meio tecnológico.

Fotos e linguagem verbal. Sim, pois foram usados

Thiago vários hiperlinks que redirecionavam para a história dele. (Sic)

Linguagem verbal, vídeos, imagens. Acho muito

Marília interessante o recurso de vídeo, principalmente para aprender a ouvir em inglês. (Sic)

Fonte: SOUZA, 2013, p. 102 
As respostas selecionadas permitem confirmar que os aprendizes usaram recursos semióticos diversos na produção do gênero biografia: Alberto: "Vídeos, fotos, linguagem e desenhos"; Rebeca: "Imagem e texto"; Thiago: "[...] foram usados vários hiperlinks que redirecionavam para a história dele". Tais respostas estão em consonância com as produções apresentadas. Também pode-se observar que a atividade proporcionou uma ampliação dos conhecimentos relacionados ao uso de ferramentas digitais, caso se considerem as palavras de Alberto: “[...] eu não sabia que existia esta ferramenta". Nesse momento, o participante alude ao Glogster: ferramenta sugerida para realização da atividade. Vale ressaltar a resposta de Raul: conforme o participante, o uso dos recursos semióticos disponíveis pelas ferramentas digitais permitiu que o pôster ficasse "[...] legal, animado, e bonito, chamando atenção das pessoas". Essa resposta permite deduzir, com base na palavra "pessoas", que o participante faz alusão à presença de outros interlocutores que não só a professora. Nesse sentido para Leffa (2016, p. 143) "a melhor maneira de ensinar uma língua é dar ao aluno um interlocutor" o autor aponta as redes sociais como um recurso promissor para aproximar o aluno de um interlocutor real.

A partir daí, há a possibilidade de um paralelo entre a resposta de Raul e as reflexões apresentadas por Bazerman (2011, p. 15) quanto ao foco da escrita escolar. Segundo esse autor, essa escrita é utilizada para identificar o que os aprendizes precisam melhorar: serve de instrumento para uma avaliação somativa e formativa. $O$ aprendiz escreve para um examinador (professor) que detectará os erros. Nesse sentido,

[...] medo da caneta vermelha indicando falhas, erros ou desempenho inadequado pode contaminar as tarefas de escrita escolar e os alunos podem limitar suas ambições relativas à sua escrita para minimizar os riscos de correção. Essa escrita para o desempenho escolar deixa os alunos com a crença de que a escrita sirva principalmente para ganhar a aprovação de uma autoridade e os deixa com medo de serem corrigidos e, dessa forma, humilhados. Essa crença nega aos alunos o sentido de todas as outras coisas que podiam realizar com a escrita. (BAZERMAN, 2011, $p$. $15)$. 
Com base nesse paralelo, pode-se dizer que Raul não demonstrou ter produzido somente para ganhar aprovação de uma autoridade - aqui, a professora. Além disso, ele se mostra preocupado com outros aspectos da escrita, a exemplo dos aspectos visuais do texto, que podem atrair a atenção do leitor e que não podem ser desconsiderados numa produção textual. Assim, optou-se por focar nas produções no desenvolvimento da criatividade, organização textual e produção de significados através da promoção do uso da LI em detrimento da correção. Para finalizar, seguem as considerações finais.

\section{Considerações finais}

Apresentamos neste artigo uma proposta de produção escrita através do uso de ferramentas digitais a qual foi apoiada em reflexões sobre leitura e escrita em na contemporaneidade: tela. Não quisemos com isso divulgar uma receita a ser seguida para o ensino de língua inglesa, mesmo porque sabemos que uma proposta que se apresenta positiva em um contexto pode não ter o mesmo resultado em outro.

Tampouco pensamos em apresentar uma solução para os problemas que nós professores da disciplina enfrentamos em contexto de escola regular. Sabemos que muitos deles fogem da nossa condição docente e requerem políticas públicas adequadas que caminhem na direção da valorização da disciplina no contexto estudado, pois não mais é necessário ressaltar a importância de se saber comunicar em língua inglesa na sociedade atual bem como no mundo de trabalho contemporâneo.

Quisemos apenas divulgar o resultado de uma pesquisa que, do nosso entendimento, foi positiva, no sentido de ter proporcionado uma ampliação do conhecimento de mundo dos aprendizes através da aprendizagem de língua estrangeira. Os dados nos mostraram que os aprendizes aprenderam através da língua inglesa, não somente sobre ela. Entendemos as limitações ainda existentes quanto ao uso das tecnologias digitais no contexto escolar, e ressaltamos a necessidade de superá-las tanto por parte de professores quanto por parte de aprendizes.

Finalizamos sugerindo o desenvolvimento de mais pesquisas que envolvam práticas de leitura e de escrita em tela, que os resultados 
possam ser compartilhados para que possamos nos encorajar a realizar possíveis mudanças e inovações no que se refere ao ensino de língua estrangeira em contexto escolar, uma vez que teremos a oportunidade de embasarmos em experiências de outros colegas de profissão.

\section{Referências}

ANTUNES, Irandé. Língua, texto e ensino: outra escola possível. 2. ed. São Paulo: Parábola, 2009.

BAZERMAN, Charles. Gênero, agência e escrita. 2. ed. São Paulo: Cortez, 2011.

BOGDAN, Robert C.; BIKLEN, Sari. K. Qualitative research for education: an introduction to theory and methods. Needham Heights, MA: Allyn \& Bacon, 1998.

BRASIL. Ministério da Educação Básica. Orientações curriculares nacionais para o ensino médio. Linguagens, códigos e suas tecnologias. Brasília: Ministério da Educação, Secretaria de Educação Básica, 2006.

CARR, Wilfred.; KEMMIS, Stephen. Becoming critical education: on knowledge and action research. London and Philadelphia: The Palmer Press, 1986. Disponível em:

<http://enotez.files.wordpress.com/2011/09/becoming-critical.pdf〉. Acesso em: 18 fev. 2013.

DIAS, Reinildes. Gêneros digitais e multimodalidade: oportunidades on-line para a escrita e a produção oral em inglês no contexto da educação básica. In: DIAS, R.; DELL'ISOLA, R. L. P. (Org.). Gêneros textuais: teoria e prática de ensino em LE. Campinas: Mercado das Letras, 2012b, p. 295-315.

DIAS, Reinildes. WebQuests: tecnologias, multietramentos e a formação do professor de inglês para a era do ciberespaço. Revista Brasileira de Linguística Aplicada, v. 12, p. 861-81, 2012a. Disponível 
Sheilla Andrade Souza; Maria da Glória Magalhães dos Reis

em: < http://www.scielo.br/pdf/rbla/2012nahead/aop1212.pdf>. Acesso em: 15 abr. 2013.

DIONÍSIO, Angela P. Gêneros textuais e multimodalidade. In: KARWOSKI. A. M.; GAYDECZKA. B.; BRITO. K. S.; (Org.). Gêneros textuais: reflexões e ensino. 4. ed. São Paulo: Parábola, 2011, p. 137-52.

DOLZ, Joaquim et al. Sequências didáticas para o oral e a escrita: apresentação de um procedimento. In: SCHNEUWLY, Bernard; DOLZ, Joaquim. Gêneros orais e escritos na escola. Tradução de Roxane Rojo e Glaís Sales Cordeiro. Campinas: Mercado das Letras, 2004. p. 95-128.

FREIRE, Paulo. Pedagogia do oprimido. Rio de Janeiro: Paz e Terra, 1970.

KALANTZIS, Marry; COPE, Bill. Literacies. Port Melbourne: Cambridge University Press, 2012.

KRESS, Gunther. Literacy in the new media age. London, New York: Routledge, 2003.

KRESS, Gunther; VAN LEEUWEN, Theo. Reading images: the grammar of visual design. 1 ed. London, New York: Routledge, 1996.

KRESS, Gunther; VAN LEEUWEN, Theo. Reading images: the grammar of visual design. 2 ed. London, New York: Routledge, 2006.

LEFFA, Vilson. Redes sociais: ensinando línguas como antigamente. In: ARAÚJO, J; LEFFA, V. Redes sociais e ensino de línguas: o que temos de aprender? 1.ed. São Paulo: Parábola Editorial, 2016.

MARCUSCHI, Luiz A. Gêneros textuais: configuração, dinamicidade e circulação. In: KARWOSKI. A. M.; GAYDECZKA. B.; BRITO. K. S. (Org.). Gêneros textuais: reflexões e ensino. 4. ed. São Paulo: Parábola, 2011, p. 16-31. 
MATTOS, Andréa M. A. Novos letramentos, ensino de línguas estrangeiras e o papel da escola pública no séc. XXI. Revista X, v. 1, p. 33-47, 2011.

NORTON, Bonny; TOOHEY, Kelleen. Identity, language learning, and social change. Language Teaching, n. 44, v. 4, p. 412-46. (Stateof-the-Art Article). Disponível em: <http://educ.ubc.ca/faculty/norton/Norton\%20and\%20Toohey\%20Lan guage\%20Teaching\%202011.pdf >. Acesso em: nov. 2011.

PIMENTA. Sônia M. O; MAIA. Denise G. Multimodalidade e letramento: análise da propaganda Carrossel. Revista do Programa de Pós-Graduação em Letras da Universidade de Passo Fundo, v. 10, n. 1, p. 126-148, jan/jun. 2014.

ROJO, Roxane; Protótipos didáticos para os multiletramentos. In: ROJO. R.; MOURA, E. (Org.). Multiletramentos na escola. São Paulo: Parábola, 2012, p. 7-31.

SCHNEUWLY, Bernard; DOLZ, Joaquim. Gêneros orais e escritos na escola. Tradução de Roxane Rojo e Glaís Sales Cordeiro. Campinas: Mercado das Letras, 2004.

SOARES, Magda. Letramento: um tema em três gêneros. 4. ed. Belo Horizonte: Autêntica, 2010.

SOARES, Magda. Novas práticas de leitura e escrita: letramento na cibercultura. Educ. Soc., Campinas, v. 23, n. 81, p. 143-60, dez. 2002.

SOUZA, Sheilla A. Ressignificando o ensino de inglês instrumental em contexto de educação profissional de nível médio: uma proposta baseada em sequência didática. 2013 [trabalho em fase de prépublicação no banco de dissertações e teses]. 142 f. Dissertação (Mestrado em Linguística Aplicada) - Departamento de Línguas Estrangeiras e Tradução, Universidade de Brasília. 
Sheilla Andrade Souza; Maria da Glória Magalhães dos Reis

SOUZA, Sheilla A. REIS, Maria da Glória M. Sequência Didática e Gêneros Textuais: uma Proposta Pedagógica. SIGNUM: Estudos da Linguagem, Londrina, v. 17, n. 2, p. 32-64, 2014.

WALSH, Maureen. Pedagogic potentials of multimodal literacy. Disponível em:

<http://www.acu.edu.au/_data/assets/pdf_file/0007/195676/Chapter_ 3_Multimodal_Literacy_M_Walsh.pdf>. Acesso em: 29 ago. 2015.

XAVIER, Antonio Carlos S. Letramento digital e ensino. In: SANTOS, Carmi F.; MENDONÇA, Márcia. (Orgs.). Alfabetização e letramento: conceitos e relações. 1 ed. Belo Horizonte: Autêntica, 2005.

Recebido em: 31/08/16

Aceito em: 22/11/16

Title: Reading and writing practices in a contemporary society: a multimodal production 